ABDI: Jurnal Pengabdian dan Pemberdayaan Masyarakat ISSN: 2656-369X (Print), 2684-8570 (Online)

Volume 2 No. 1, Juni 2020

http://abdi.ppj.unp.ac.id/index.php/abdi

Email: abdi@ppj.unp.ac.id

DOI: https://doi.org/10.24036/abdi.v2il.24

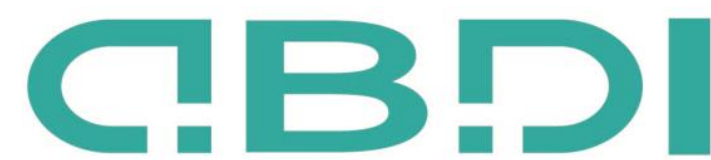

ABDI: JURNAL PENGABDIAN DAN PEMBERDAYAAN MASYARAKAT

\title{
Diklat Relawan Anti Narkoba sebagai Partisipasi dalam Pemberantasan Penyalahgunaan Narkoba
}

\author{
Irwan Kurniawan Soetijono ${ }^{1}$, Rudi Mulyanto ${ }^{2}$, Marwiyah ${ }^{3}$ \\ ${ }^{1,2,3}$ Program Studi Hukum, Universitas 17 Agustus 1945 Banyuwangi
}

Email: irwankurniawan616@gmail.com, notaris.rm@gmail.com, notaris_wiwik11@yahoo.com

\begin{abstract}
Abstrak
Narkotika dan obat-obatan terlarang telah lama menjadi keprihatinan kita semua. Jumlah penyalahguna dan pengedar narkotika dan obat-obatan terlarang semakin meningkat baik dari segi kuantitas maupun kualitasnya. Pengguna narkotika dan obat-obatan terlarang tidak memandang status ekonomi, wilayah tempat tinggal, profesi dan usia, bahkan terdapat kecenderungan pengguna narkotika dan obatobatan terlarang semakin meluas di kalangan generasi muda. Tentu hal ini menjadi keprihatinan seluruh masyarakat. Pemberantasan penyalahgunaan dan peredaran narkotika, selain wajib menjadi program prioritas bagi pemerintah, penting juga bagi menumbuhkan partisipasi masyarakat. Salah satunya mengakomodasi keinginan masyarakat untuk berperan serta menjadi relawan anti penyalahgunaan narkotika dan obat-obatan terlarang atau narkoba. Relawan anti narkoba diharapkan mampu menjadi agen perubahan (agent of change) yang mampu menggerakkan partisipasi aktif seluruh komponen masyarakat. Salah satunya melalui Pendidikan dan Latihan (Diklat). Pendidikan dan Latihan (Diklat) Dasar Relawan Narkoba yang diselenggarakan oleh Lembaga Rehabilitasi Pencegahan Penyalahgunaan Narkotika (LRPPN) Bhayangkara Indonesia Kabupaten Banyuwangi, berkolaborasi dengan Klinik Dokter Didik Sulasmono (KDS), Lembaga Aliansi Indonesia (LAI), Universitas 17 Agustus 1945 Banyuwangi (UNTAG BANYUWANGI). Kegiatan Diklat diharapkan mampu menghasilkan relawan yang menjadi garda terdepan dalam pencegahan, pemberantasan dan penyebaran informasi terhadap bahaya narkoba.
\end{abstract}

Kata Kunci : Anti Narkoba, Parisipasi, Pemberantasan Penyalahgunaan, Relawan

\section{Abstract}

Narcotics and illegal drugs have long been a concern to all of us. The number of abusers and drug dealers and illegal drugs is increasing both in terms of quantity and quality. Users of narcotics and illicit drugs do not view the economic status, territory of residence, profession and age, and there is even a tendency for narcotics and illegal drugs to become increasingly widespread among younger generations. Naturally this concerns the whole community. Eradicating the misuse and circulation of narcotics, in addition to being a priority program for the Government, is also important to foster community participation. One of them accommodates people's desire to participate in volunteering for narcotics anti-abuse and illegal drugs or drugs. Anti-drug volunteers are expected to become agent of change capable of driving active participation of all components of the community. One of them is through education and training (Diklat). Education and Training (training) on the basis of drug volunteers organized by Narcotics Rehabilitation Prevention Institute (LRPPN) Bhayangkara Indonesia Banyuwangi Regency, in collaboration with the Doctor of Didik Sulasmono (KDS), Institute of Alliance of Indonesia (LAI), university 17 August 1945 Banyuwangi (UNTAG BANYUWANGI). Training activities are expected to produce volunteers who become the leading guard in the prevention, eradication and dissemination of information on drug hazards

Key Words: Anti-drugs, Eradication of abuse, Participation, Volunteers

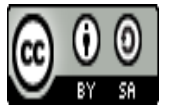

Received: 3 Desember $2019 \quad$ Revised: 13 Januari $2020 \quad$ Available Online: 15 Januari 2020




\section{Pendahuluan}

Saat ini permasalahan penyalahgunaan dan peredaran gelap narkotika dan obat-obatan terlarang (narkoba) semakin mengkhawatirkan. Indonesia semakin memasuki situasi darurat narkoba. Bahkan disinyalir Indonesia bukan hanya sebagai tempat transit narkoba, tapi telah menjadi pasar utama peredaran jaringan internasional narkoba. Perkembangan jaman yang semakin pesat tidak hanya membawa dampak positif bagi kehidupan manusia namun juga menimbulkan berbagai masalah baru yang sulit untuk dihindari. Termasuk masalah anak pun menjadi semakin kompleks. (Rahmi, L, 2019)

Berdasarkan data Badan Narkotika Nasional (BNN), bahwa tidak ada satupun Kabupaten/ Kota yang bebas dari peredaran dan penyalahgunaan pemakaian gelap narkoba. Penyalahgunaan dan peredaran gelap narkotika dan obat-obatan terlarang merupakan kasus yang semakin hari semakin mengalami peningkatan. Peningkatan tersebut meliputi baik dari segi kuantitas maupun kualitas. Data menunjukkan sebagian besar penyalahguna narkotika dan obat-obatan terlarang adalah generasi muda yang nota bene merupakan usia produktif. Dampak buruk penyalahgunaan narkotika dan obat-obatan terlarang adalah menimbulkan ketergantungan bagi pemakainya, di samping akibat buruk bagi kesehatan. Dampak buruk bagi kesehatan baik fisik maupun jiwa antara lain adalah dehidrasi, turunnya tingkat kesadaran, turunnya kualitas hidup, halusinasi bahkan menyebabkan kematian. (Eleanora, Fransiska Novita, 2011) Maraknya penyalahgunaan dan peredaran gelap narkotika dan obat-obatan terlarang terjadi tidak hanya di wilayah kota. Bahkan di desa dengan sarana prasarana serta infrastruktur minim, penyalahgunaan dan peredaran gelap narkotika dan obat-obatan terlarang acap ditemukan oleh pihak berwajib. Hal ini selain menghambat proses pembangunan sumber daya manusia juga menjadi beban bagi suatu daerah untuk berkembang. Karena kasus penyalahgunaan dan peredaran gelap narkotika dan obat-obatan terlarang senantiasa diiringi dengan timbulnya permasalahan sosial. (Yusfar, Nurhayani, Balqis, 2013). Hal ini juga berkaitan dengan ketergantungan seperti rokok. Kecenderungan siswa perokok juga akan berteman dengan teman yang juga seorang perokok (Zulfa, A., Erianjoni, E., \& Isa Gautama, M, 2019)

Di Indonesia, narkotika dan obat-obatan terlarang diatur dalam Undang-Undang Nomor 35 Tahun 2009 Tentang Narkotika. Narkotika adalah zat atau obat yang berasal dari tanaman atau bukan tanaman, baik sintetis maupun semisintetis, yang dapat menyebabkan penurunan atau perubahan kesadaran, hilangnya rasa, mengurangi sampai menghilangkan rasa nyeri, dan dapat menimbulkan ketergantungan, yang dibedakan ke dalam golongan-golongan sebagaimana terlampir dalam UndangUndang ini (Simangunsong, Jimmy, 2015). tak hanya kerupuk jenis makanan lainnya juga patut dicurigai, tapi pewarna merah pada sosis yang dijual pedagang keliling dan pemanis pada minuman gelas dansachet cukup membuat kerongkongan panas saat diminum karena teramat manisnya minuman tersebut.

Semakin meluasnya peredaran dan penyalahgunaan narkoba tentu tidak cukup hanya ditangani oleh pemerintah. Dibutuhkan partisipasi aktif seluruh lapisan masyarakat untuk ikut serta dalam pencegahan peredaran dan penyalahgunaan narkoba. Melalui forum anti narkoba, sosialisasi dan diseminasi serta pendidikan dan latihan (Diklat) diharapkan menumbuhkan kesadaran masyarakat mengenai ancaman bahaya peredaran dan penyalahgunaan pemakaian narkoba. (Andriyani, Titi, 2011)

Berdasarkan latar belakang tersebut dibutuhkan kolaborasi seluruh lapisan masyarakat untuk menambah informasi mengenai narkoba dan dampak penyalahgunaannya (Amriel, R. I, 2008). Gejala pemakai narkoba dan rehabilitasi baik medis maupun sosial diperlukan sebagai bekal untuk mendapatkan solusi terbaik penyelesaian masalah narkoba. Saat ini masyarakat semakin peduli akan ancaman bahaya narkoba. Masyarakat mulai mencari informasi peredaran narkoba sekaligus pencegahan penyalahgunaan pemakaian narkoba. Akan tetapi masyarakat terkendala minimnya program dan kegiatan rutin yang diadakan oleh pemerintah terkait upaya pencegahan dan rehabilitasi narkoba. Hal ini terjadi karena memang daya jangkau pemerintah terbatas dibandingkan cepatnya peredaran dan penyalahgunaan narkoba. Diperlukan sinergi pemangku kepentingan untuk menfasilitasi keinginan masyarakat tersebut (Gunawan, W, 2006).

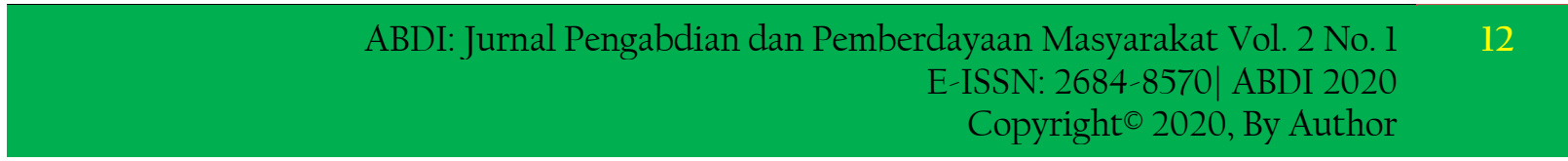


Kegiatan Pengabdian Kepada Masyarakat ini bertujuan untuk memberikan pengetahuan tentang informasi dan upaya pencegahan dan pemberantasan dan penyalahgunaan peredaran gelap narkotika dan obat-obatan terlarang. Melalui Pendidikan dan Pelatihan bagi relawan anti Narkoba, diharapkan memberikan kontribusi bagi masyarakat baik secara teoritis maupun praktis dalam pencegahan maraknya peredaran narkotika.

Kegiatan pendidikan dan latihan ini diharapkan menjadi wadah bagi masyarakat yang berkeinginan menjadi relawan anti narkoba. Kegiatan yang diselenggarakan secara sistematis dan terencana serta disampaikan oleh pemateri yang kompeten dibidangnya diharapkan mampu memberikan ilmu dan praktek terkait informasi peredaran narkoba, akibat penyalahgunaan narkoba, kerelawanan, dasar hukum terkait narkoba, rehabilitasi medis dan sosial serta sel-healing. Kegiatan diklat mampu membangun jaringan relawan anti narkoba.

\section{Metode Pelaksanaan}

Metode yang digunakan dalam pelaksanaan kegiatan Pengabdian Kepada Masyarakat ini adalah pembekalan secara teoritis, diskusi antar peserta diklat, serta simulasi dan umpan balik dari peserta Diklat. Dalam pembekalan, disampaian bahwa relawan bekerja berdasarkan asas Pancasila dan UUD 1945. Selanjutnya dijelaskan prinsip kerja relawan yakni ikhlas, profesional, bekerja tanpa imbalan dan berintegritas. Dijelaskan pula bahwa relawan berfungsi sebagai penyuluh masyararakat untuk memberikan pengetahuan dan pemahaman melalui sosialisasi dan diskusi bahaya penyalahgunaan narkoba. Disampaikan pula bahwa relawan merupakan inisiator yang merancang dan mengimplementasikan program pencegahan secara mandiri dan relawan berfungsi juga sebagai motivator yang menggerakkan masyarakat untuk terlibat aktif dalam upaya pencegahan, peredaran dan penyalahgunaan pemakaian narkoba. Adapun materi Diklat selama dua hari pelaksanaan adalah sebagai berikut :

Tabel 1. Materi Hari Ke-1

\begin{tabular}{clc}
\hline No & \multicolumn{1}{c}{ Materi Hari Ke-1 } & $\begin{array}{c}\text { Jam } \\
\text { (Jam Pelajaran) }\end{array}$ \\
\hline Hari I & & \\
\hline 1 & Penjelasan tentang Relawan Anti Narkotika & 1 jp \\
\hline 2 & Narkotika dan Permasalahannya & 2 jp \\
\hline 3 & Narkotika dalam Perspektif Hukum & $1 \mathrm{jp}$ \\
\hline 4 & Pentingnya Rehabiltasi (Medis dan Sosial) & $1 \mathrm{jp}$ \\
\hline 5 & Pencegahan Narkoba di Lingkungan terdekat & $3 \mathrm{jp}$ \\
\hline Total Jam Pelajaran & $8 \mathrm{jp}$ \\
\hline
\end{tabular}

Tabel 2. Materi Hari Ke-2

\begin{tabular}{l|l|c}
\hline \multicolumn{1}{l|}{ No } & \multicolumn{1}{c}{ Materi Hari Ke-2 } & Jam \\
\hline \multicolumn{1}{l|}{ Hari II } & \multicolumn{1}{c}{} \\
\hline 1 & Teknik Komunikasi dan Presentasi Efektif & 4 jam \\
\hline 2 & Teknik Pemanfaatan Media Komunikasi & 2 jam \\
\hline 3 & Rencana Aksi Pencegahan dan Simulasi & 2 jam \\
\hline \multicolumn{2}{l}{ Total Jam Pelajaran } & 8 jam \\
\hline
\end{tabular}




\section{Hasil dan Pembahasan}

Pelaksaan Pendidikan dan Latihan (Diklat) Relawan anti narkoba dilaksanakan pada bulan November 2019. Dilaksanakan di Banyuwangi dengan diikuti oleh 30 peserta yang berasal dari Banyuwangi dan beberapa kota sekitarnya seperti Jember, Lumajang, Situbondo dan Bondowoso. Sebagaian peserta Diklat adalah mahasiswa Sekolah Tinggi Ilmu Kesehatan, relawan kebencanaan, aktivis lingkungan hidup dan masyarakat umum. Sedangkan pemateri dalam Diklat terdiri dari anggota Polres Banyuwangi, pengelola panti rehabilitisi, tenaga kesehatan (dokter dan perawat), praktisi hukum, akademisi bidang hukum dan relawan anti narkoba.

\section{Pengertian Relawan}

Dalam sesi pembekalan, ditekankan bahwa relawan anti narkoba adalah seseorang yang bersedia mengabdi secara tanpa pamrih, ikhlas, tanpa berharap imbalan. Kamus besar bahasa indonesia (KBBI) mengemukana relawan sebagai bentuk non-formal (tidak baku) dari sukarelawan. Artinya orang yang melakukan sesuatu tanpa paksaan dan bukan karena sebuah kewajiban. Dapat disimpulkan bahwa relawan /sukarelawan yaitu individu yang mengambil peran atau melakukan kegiatan tertentu atas motif suka dan rela. Adapun padanan kata dalam bahasa Inggris disebut sebagai volunteer.

Dalam pembekalan disampaikan bahwa relawan anti narkoba memiliki tugas sebagai penyuluh, yakni menyebarluaskan informasi tentang pencegahan dan pemberantasan penyalahgunaan dan peredaran gelap narkotika dan obat-obatan terlarang. Tugas berikutnya adalah menginisiasi program dan kegiatan terkait pencegahan dan pemberantasan penyalahgunaan dan peredaran gelap narkotika dan obat-obatan terlarang. Sebagai motivator, relawan anti narkoba diharapkan mampu memberikan motivasi kepada keluarga, rekan, pelajar/ mahasiswa serta masyarakat tentang pencegahan dan pemberantasan penyalahgunaan dan peredaran gelap narkotika dan obat-obatan terlarang.

\section{Kegiatan Diklat}

Meskipun dilaksanakan dalam waktu yang terbatas dengan materi yang beragam, diharapkan peserta Diklat dapat mengikuti tahapan materi secara tuntas. Adapun tahapan dan materi pelaksanaan diklat yang adalah :

a. Pendaftaran. Sebagai tahap awal, calon relawan menyerahkan persyarakat administrasi yang telah ditentukan oleh panitia, antara lain identitas diri. Dari segi biaya, peserta Diklat tidak dikenakan biaya. Baik biaya pelatihan, akomodasi maupun konsumsi. Dalam tahapan ini, juga dilakukan wawancara singkat tentang latar belakang relawan dan motivasi relawan dalam mengikuti diklat. Dalam tahapan ini disampaikan juga tahapan yang wajib dilalui oleh peserta dan gambaran materi yang akan diikuti oleh peserta Diklat.

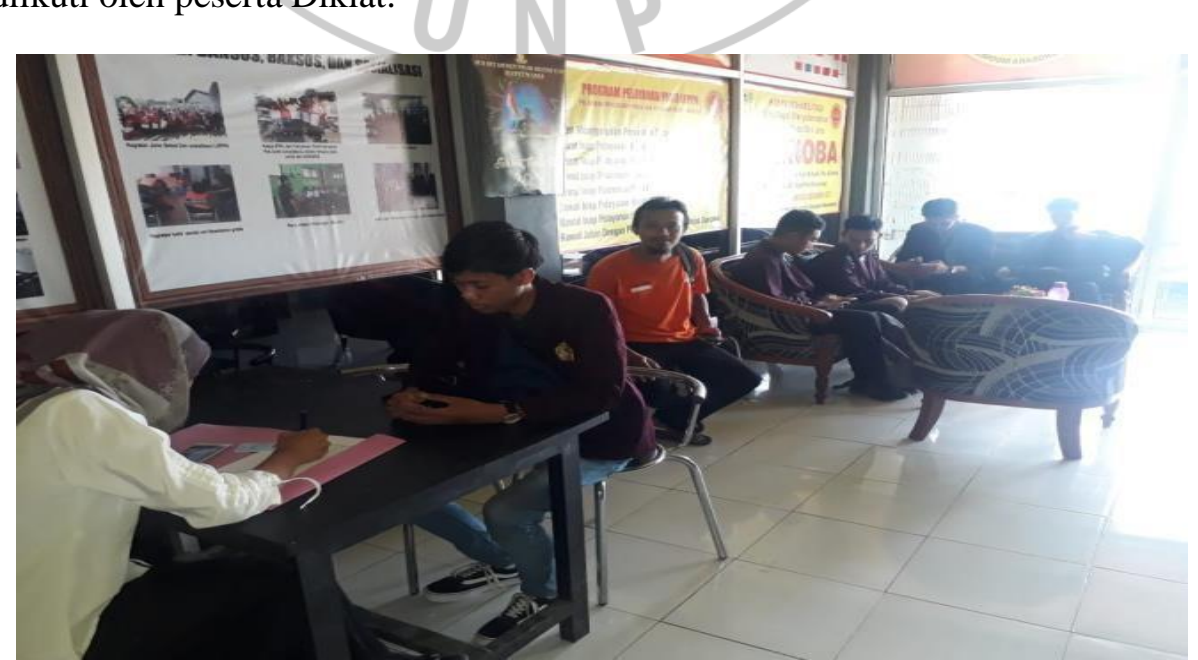

Gambar 1. Pendaftaran dan wawancara peserta Diklat 
b. Pembekalan. Dalam tahapan ini disampaikan perkembangan terkini terkait narkoba di Indonesia. Pemeritah semakin serius menghadapi penyalahgunaan dan peredaran gelap narkoba. Penguatan lembaga negara anti narkoba dan penambahan anggaran merupakan salah satu bentuknya. Aparat hukum juga semakin tegas terhadap pelaku penyalahgunaan narkoba.

Dalam materi terkait sanksi hukum, diatur dalam Undang-undang No 35 Tahun 2009 tentang Narkotika. Untuk golongan I diatur dalam Pasal 111 dan 112 mengenai Kepemilikan, Pasal 113 (Produsen), Pasal 114 (Pengedar), Pasal 115 (Kurir Narkoba) dan Pasal 116 terkait Seseoran yang menyuntikkan narkoba kepada orang lain.

c. Dalam rehabilitasi dikenal dua jenis pelaksanaan yaitu rehabilitasi medis dan rehabilitasi sosial. Rehabilitasi Medis, merupakan suatu proses kegiatan pengobatan secara terpadu untuk membebaskan pecandu dari ketergantungan Narkoba. Sedangkan rehabilitasi sosial yaitu proses kegiatan pemulihan secara terpadu, terkait fisik, mental maupun sosial. Setelah menjalalani rehabilitasi sosial diharapkan mantan pecandu mampu kembali melaksanakan fungsi sosial dalam kehidupan sebagai bagian anggota masyakarakat.

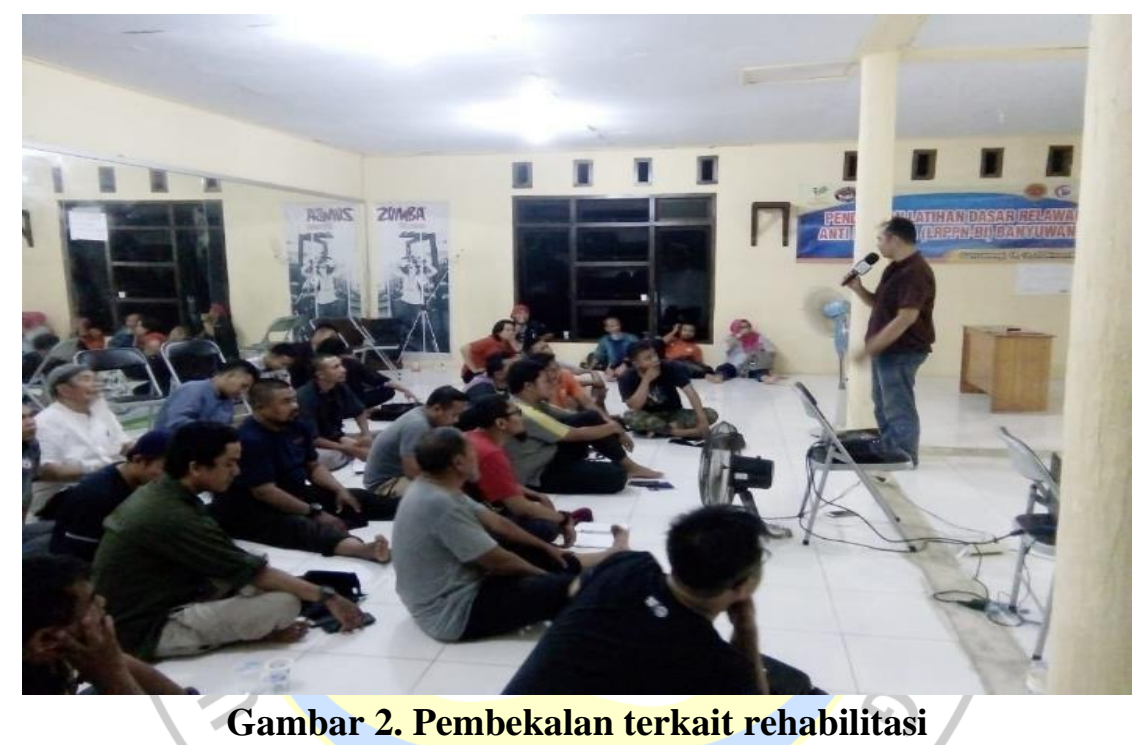

d. Terkait keterampilan berkomunikasi, relawan anti narkoba diharapkan mampu berkomunikasi baik secara langsung maupun tidak langsung. Tujuannya agar relawan dapat menyebarkan informasi melalui berbagai macam media mulai media off line maupun media on line / media sosial. Relawan juga dibekali kemampuan terkait story telling dan metode penyampaian pesan secara persuasif sehingga mampu mempengaruhi orang lain dalam hal ini mencegah penyalahgunaan pemakaian narkoba hingga mampu mendampingi pemakai narkoba dalam kegiatan rehabilitasi.

e. Simulasi. Simulasi diartikan sebagai gambaran atau tindakan tiruan dengan tujuan untuk menggambarkan suatu keadaan atau peristiwa yang akan terjadi agar lebih jelas. Dalam Diklat relawan anti narkoba, simulai bertujuan agar rencana program kegiatan yang telah disusun, didiskusikan dan dievaluasi menjadi lebih jelas dan lebih masuk akal ketika dilakasanakan dalam dunia kerelawanan. 


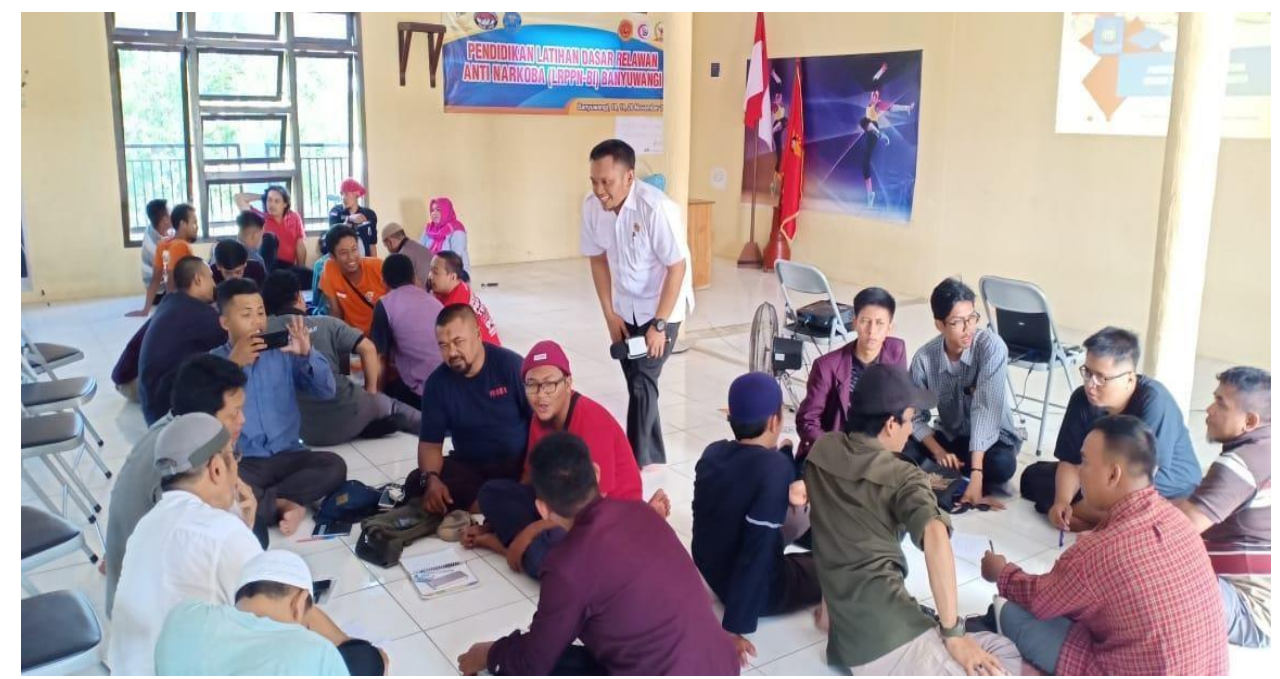

Gambar 3. Diskusi dan simulasi

\section{Kesimpulan}

Pendidikan dan latihan (Diklat) Relawan anti narkoba merupakan salah satu bentuk partisipasi aktif masyarakat dalam upaya pencegahan peredaran penyalahgunaan pemakaian narkotika dan obatobatan terlarang. Rangkaian kegiatan yang dilaksanakan dalam 2 (dua) hari disusun secara sistematis agar relawan mendapatkan pengetahuan dan keterampilan yang komprehensif meskipun sifatnya mendasar. Kegiatan Diklat mencakup pendidikan dan pelatihan, perencanaan, pengembangan kapasitas, serta pengendalian kegiatan kerelawanan. Diharapkan akan menghasilkan relawan yang konsisten mendukung pelaksanaan kegiatan pencegahan penyalahgunaan peredaraan penggunaan narkoba sekaligus pemberdayaan masyarakat. Diklat yang bermaterikan pengetahuan dasar narkoba dan permasalahannya, konsep rehabilitasi, perspektif hukum hingga strategi berkomunikasi dalam melaksanakan kegiatan penyuluhan dan usaha untuk mendorong partisipasi aktif masyarakat melaksanakan kegiatan pencegahan berbasis kemandirian.

\section{Daftar Pustaka}

Amriel, R. I. (2008). Psikologi Kaum Muda Pengguna Narkoba. Jakarta: Penerbit Salemba.

Andriyani, Titi. (2011). Upaya Pencegahan Tindak Penyalahgunaan Narkoba Di Kalangan Mahasiswa Politeknik Negeri Sriwijaya. Jurnal Ilmiah Orasi Bisnis, 4(1).

Eleanora, Fransiska Novita. (2011). Bahaya Penyalahgunaan Narkoba Serta Usaha Pencegahan Dan Penanggulangannya (Suatu Tinjauan Teoritis). Jurnal Hukum, 25(1).

Gunawan, W. (2006). Keren Tanpa Narkoba. Jakarta: Grasindo

Rahmi, L. (2019). Pengembangan Self-Efficacy Pelajar Melalui Pendidikan Seks Dini Guna Mencegah Pelecehan Seksual Pada Anak. ABDI: Jurnal Pengabdian Dan Pemberdayaan Masyarakat, 1(2), 84-87. https://doi.org/10.24036/abdi/vol1-iss2/22

Ricardo, P. (2010). Upaya Penanggulangan Penyalahgunaan Narkoba oleh Kepolisian (Studi Kasus Satuan Narkoba Polres Metro Bekasi). Indonesian Journal of Criminology, 4(1).

Selinaswati, S. (2018). Peran Sekolah Dalam Antisipasi Keracunan Pangan Jajanan Anak SekolahPjas. Socius, 4(2), 126-133. doi:10.24036/scs.v4i2.18

Simangunsong, Jimmy. (2015). Penyalahgunaan Narkoba Di Kalangan Remaja (Studi kasus pada Badan Narkotika Nasional Kota Tanjungpinang ).Tesis. Universitas Maritim Raja Ali Haji Tanjungpinang.

Yusfar, Nurhayani, Balqis. (2013). Faktor yang Berhubungan dengan Kualitas Layanan Rehabilitasi Penyalahgunaan Narkoba di Balai Rehabilitasi Badan Narkotikan Nasional Baddoka Makassar Tahun 2013. Tesis. Universitas Hasanudin. 

Diklat Relawan Anti Narkoba sebagai Partisipasi dalam Pemberantasan Penyalahgunaan Narkoba

Zulfa, A., Erianjoni, E., \& Isa Gautama, M. (2019). Perilaku Siswa Dalam Clique Perokok Elektrik Vaporizer Di Sma Negeri 15 Padang. Jurnal Perspektif, 2(1), 12-19. doi:10.24036/perspektif.v2i1.62

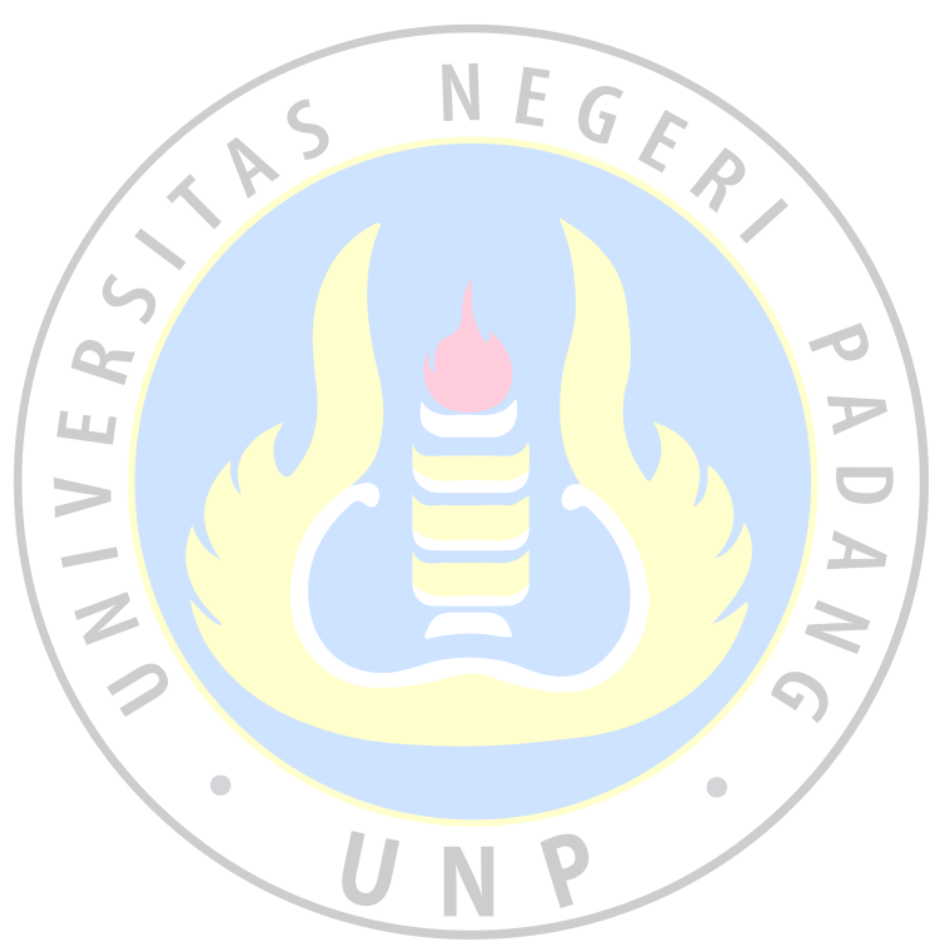

